\title{
Evaluation of Sanazole Cytotoxicity in Human Drug-Sensitive and MDR Uterine Sarcoma Cells
}

\author{
Mariame A Hassan ${ }^{1,2}$, Yukihiro Furusawa ${ }^{3}$, Seisukei Okazawa ${ }^{1,4}$, Kazuyuki Tobe ${ }^{4}$ and Takashi Kondo ${ }^{1 *}$ \\ ${ }^{1}$ Department of Radiological Sciences, Graduate School of Medicine and Pharmaceutical Sciences, University of Toyama, Sugitani 2630, Toyama 930-0194, Japan \\ ${ }^{2}$ Department of Pharmaceutics and Industrial Pharmacy, Faculty of Pharmacy, Cairo University, Kasr Al-Aini str., Cairo 11562, Egypt \\ ${ }^{3}$ Laboratory for Mucosal Barriology, International R\&D Center for Mucosal Vaccination, The Institute of Medical Science, The University of Tokyo, Tokyo, 108-8639 Japan \\ ${ }^{4}$ Department of Internal Medicine, Graduate School of Medicine and Pharmaceutical Sciences, University of Toyama, Sugitani 2630, Toyama 930-0194, Japan
}

\begin{abstract}
Chemotherapy is one of the principle modes of cancer treatment. However, cells adapt to repeated chemotherapeutic exposures in several ways resulting in multidrug resistance (MDR). Therefore, it is mandatory to search for effective alternatives that are refractory to resistant mechanisms. In this study, we investigated the cytotoxicity of sanazole, a nitrotriazole derivative known for its hypoxic radio-sensitization, against a human MDR cell line highly expressing P-glycoprotein that functions as an efflux pump to lipophilic drugs. The results showed that MDR cells exhibited initial sensitivity to the drug compared to the parent sensitive cells. Sanazole action was independent of the degree of resistance and P-glycoprotein expression. Prolonged exposures ( $48 \mathrm{~h}$ ) to the drug affected both cell phenotypes viability to a similar extent. However, cell cycle analysis revealed that the underlying pathways differed between cells with respect to their p53 status. For instance, cell cycle was halted in G1- and S-phase in parent and MDR cells, respectively. The (apoptotic) DNA fragmentation in MDR cells was dose-dependently higher compared to the parent cells. Sanazole treatment decreased polyploidy in a dose-dependent manner in MDR cells. The present study provides evidence on the possible potential of sanazole multidrug resistant cancer cells.
\end{abstract}

Keywords: Cytotoxicity; Multidrug resistance; Sanazole; P-glycoprotein; p53

\section{Introduction}

"Is resistance Useless?" A question that has been raised by Hall et al. [1] upon reviewing the concept of collateral sensitivity [1]. In that review, the authors mentioned that the development of multidrug resistance in unlikely to be avoidable during cancer treatment. In response to this clinical fact, researchers have been devoted to identify and understand the mechanisms of resistance. Meanwhile, most of the trodden roads to ameliorate this phenomenon have led to what is called the "face-to-face combat" in which the primary aim is to interfere with the pathways inducing resistance. For instance, multidrug resistance has been shown to be mediated primarily by the reduction of intracellular accumulation of chemotherapeutics. This reduction is achieved usually through the expression of transmembrane proteins (adenosine triphosphate (ATP) - binding cassette (ABC) transporters) that function as efflux pumps in a non-specific manner and can thus extrude a wide range of structurally unrelated lipophilic compounds out of the cells against their concentration gradients. Over the last decades, trials have been made to overcome the action of these proteins through the development of inhibitors [2], membrane modification [3-5], dosage form manipulation [6,7], etc. Recently, genetic and transcriptional targeting of biomolecules imparting resistance has been an active area of research despite the difficulties encountered in achieving efficient uptake and reasonable cost [8]. This approach proved feeble and unsatisfactory probably because cells hardly employ one mechanism for resistance. However, another alternative to eradicate resistant cancer cells is to approach them at other sites or to employ their exact adaptive resistive mechanisms as a weapon against them using different drugs.

Here, we present sanazole as a candidate drug to investigate its efficacy against multidrug resistant as well as sensitive cells. Sanazole (AK-2123;N-(2-methoxyethyl)-2-(3-nitro-1,2,4-triazol-1-yl) acetamide) has long been known as a promising hypoxic radiosensitizer since it was synthesized and tested in 1986 [9]. Compared to other hypoxic radiosensitizers, sanazole as a nitrotriazole derivative (Figure 1), has lower general toxicity, higher radiosensitizing effect [10-12] and, moreover, possesses a cytostatic and antimetastatic properties of its own $[13,14]$. In fact, sanazole can be considered as a bioreductive drug which is reduced inside the cell to give its active metabolites and/ or nitroradicals. Those products can react with essential biomolecules as such or aid in elevating the intracellular oxidative stress resulting in cell death. Though the exact active products are not known, yet, the activation process has been attributed to xanthine oxidase and

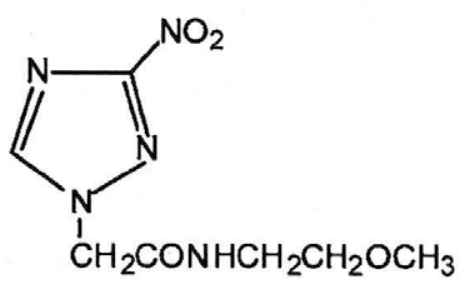

Figure 1: The structure of Sanazole (AK-2123): A nitrotriazole derivative frist known for being a hypoxic radiosensitizer. Chemical name: $\mathrm{N}$-(2-methoxyethyl)2-(3-nitro-1,2,4-triazol-1-yl) acetamide)

*Corresponding author: Takashi Kondo, Department of Radiological Sciences Graduate School of Medicine and Pharmaceutical Sciences, University of Toyama, Sugitani 2630, Toyama 930-0194, Japan, Tel: +81-(0)76-434-7265; Fax: +81-(0)76-4345190; E-mail: kondot@med.u-toyama.ac.jp

Received October 16, 2013; Accepted November 27, 2013; Published November 29, 2013

Citation: Hassan MA, Furusawa Y, Okazawa S, Tobe K, Kondo T (2013) Evaluation of Sanazole Cytotoxicity in Human Drug-Sensitive and MDR Uterine Sarcoma Cells. Pharmaceut Anal Acta 4: 275. doi: 10.4172/2153-2435.1000275

Copyright: (c) 2013 Hassan MA, et al. This is an open-access article distributed under the terms of the Creative Commons Attribution License, which permits unrestricted use, distribution, and reproduction in any medium, provided the original author and source are credited. 
NADPH/cytochrome P450 reductase [15]. As implied, sanazole effect is attributed to its ability to mimic oxygen in being an electron affinic compound stably accommodating a one-electron, thus its efficacy might be more acknowledged in the absence of oxygen (hypoxic conditions), however, we have previously shown that it can be useful under normoxic conditions [16-18].

This work comes as fourth in a row demonstrating the potential of sanazole under normoxic conditions and, as far as we know, the first to investigate sanazole effect in an in vitro model of human multidrug resistant cells highly expressing P-glycoprotein (p-gp, the oldest known member of ABC efflux proteins) using clinically relevant doses.

\section{Materials and Methods}

\section{Cell lines}

Human uterine sarcoma (MES-SA cells) [19] and its multidrug resistant phenotype (MES-SA/DX5) [20] were obtained from American Type Culture Collection (ATCC; Manassas, VA, USA). Cells were generally maintained in complete McCoy's $5 \mathrm{~A}$ medium (Gibco BRL, Grand Island, NY, USA) containing 10\% fetal bovine serum and $1 \%$ antibiotic mixture. A non-enzymatic cell dissociation solution (SigmaAldrich, St. Louis, MO, USA) was used for detaching the cell monolayer during splitting and cell culture. MES-SA/DX5 was treated with $500 \mathrm{nM}$ for $1 \mathrm{~h}$ once every 8 passages to maintain their Dox resistance [21]. For this study, MES-SA/DX5 cells were plated at a density of $1 \times 10^{3}$ cells $/ \mathrm{ml}$ in $10-\mathrm{cm}$ dishes and maintained in complete medium containing $0.5 \mu \mathrm{M}$ doxorubicin for 2 weeks to select cells with higher levels of resistance. Selected colonies were individually dissociated using $5 \mathrm{~mm}$ stainless steel cloning cylinder sealed with sterile high-vacuum grease and the resulting cell suspensions were further cultured in a 24 -well plate. The medium was replaced every $48 \mathrm{~h}$, and when confluent, the cells were collected and placed in 6-well plates. Ten colonies were separated and stocked. In our experiments, only one clone (clone V, referred to in the text as MES-SA/DX5v) was used after confirming resistance and P-gp expression.

\section{Drugs}

Sanazole was kindly provided as a gift by Emeritus Prof. Tsutomu Kagiya, Kyoto University, Japan. Doxorubicin $\mathrm{HCl}$ (Dox) was purchased from Sigma-Aldrich (St. Louis, MO, USA). Both sanazole and Dox were dissolved in sterile phosphate buffered saline (PBS). The final stock solution of San was $100 \mathrm{mM}$ whereas that of Dox was $10 \mu \mathrm{M}$. Aliquots of the stock solution were kept at $-20^{\circ} \mathrm{C}$ until use.

\section{Cytotoxicity assay}

Twenty-four hours before experiments, the cells were plated in a 96well plate at a density of 8000 cells/well in fresh complete medium. Cells were then allowed to incubate with different concentrations of sanazole and/or Dox. Following the designated incubation period for each experiment ( 24 or $48 \mathrm{~h}$ ), $10 \mu \mathrm{l}$ of the tetrazolium salt (Cell Counting Kit-8 (CCK-8); Dojindo Molecular Technologies, Inc., Rockville, MA, USA) were added to each well and incubated for $4 \mathrm{~h}$ before the color density of the soluble formazan dye product was measured at $450 \mathrm{~nm}$. Each assay was performed in duplicates and McCoy's 5A medium was used as a blank control. Untreated controls were taken as $100 \%$ viability.

\section{P-glycoprotein detection}

MES-SA, MES-SA/DX5 and MES-SA/DX5v cells were collected and fixed with $4 \%$ freshly prepared paraformaldehyde (PFA)/PBS for $30 \mathrm{~min}$ at room temperature. After thorough washings, fixed cells were incubated for $30 \mathrm{~min}$ at room temperature with $2 \%$ bovine serum albumin (BSA)/PBS to block non-specific binding. Cells were then reacted sequentially with the primary monoclonal antibody $(\mathrm{mAb})$ Anti-Pgp/MDR1 mAb (Clone: MRK16) (Kyowa Medex, Tokyo, Japan) and the secondary antibody Alexa Fluor 488 anti-mouse F (ab') IgG (Cell Signaling Technology, Beverly, MA, USA) for at least $1 \mathrm{~h}$ for each antibody before they were analyzed flow cytometrically (Epics XL, Beckman Coulter, Miami, FL, USA).

\section{Cell cycle analysis}

Control and treated cells were quantitatively collected and fixed with $70 \%$ pre-chilled ethanol for at least $2 \mathrm{~h}$. Fixed cells were resuspended in PBS containing RNAase (Nacalai Tesque, Kyoto, Japan) at a final concentration of $0.25 \mathrm{mg} / \mathrm{ml} / 1 \times 10^{6}$ cells for $30 \mathrm{~min}$ at room temperature. Cell pellets were finally suspended in $50 \mu \mathrm{g} / \mathrm{ml}$ propidium iodide (PI)/PBS staining solution and incubated in dark at $4^{\circ} \mathrm{C}$ for 20 min before flow cytometric analysis.

\section{Assessment of intracellular reactive oxygen species (ROS)}

Intracellular reactive oxygen species (ROS) were assessed at 6 and $24 \mathrm{~h}$ after treatment of cells with different doses of sanazole. The analysis was performed with flow cytometry using hydroethidine (HE) and dichlorofluorescein diacetate (DCFH-DA) (Molecular Probes, Eugene, OR, USA) $[18,22]$. Cells were collected, washed twice with PBS, and resuspended in $2 \mu \mathrm{M}$ HE or $5 \mu \mathrm{M}$ DCFH-DA in PBS. The samples were incubated at $37^{\circ} \mathrm{C}$ in the dark before flow cytometric analysis.

\section{Assessment of H2AX phosphorylation}

Cells were treated with different doses of sanazole for $24 \mathrm{~h}$ and then collected quantitatively and fixed with $70 \%$ cold methanol overnight. Cells were permealized for $30 \mathrm{~min}$ at room temperature with $0.05 \%$ Tween/PBS containing 2\% BSA to block non-specific binding. Cells were then reacted sequentially with the primary monoclonal antibody $(\mathrm{mAb})$ anti-phospho-H2AX S139 ( $\gamma \mathrm{H} 2 \mathrm{AX})$ (Upstate Biotechnology, Lake Placid, NY, USA) and the secondary antibody Alexa Fluor 488 anti-mouse F (ab') IgG (Cell Signaling Technology, Beverly, MA, USA) for at least $1 \mathrm{~h}$ for each antibody before they were analysed flow cytometrically $[23,24]$. Cells treated with Dox $(1 \mu \mathrm{M})$ for $24 \mathrm{~h}$ were used as a positive control.

\section{Western blot analysis}

Control and treated cells were suspended in lysis buffer $(50 \mathrm{mM}$ $\mathrm{NaCl}, 1 \%$ Nonidet $\mathrm{P}-40$ and $50 \mathrm{mM}$ Tris- $\mathrm{HCl}, \mathrm{pH}$ 8.0) containing protease inhibitors cocktail (Nacalai Tesque, Kyoto, Japan). SDSpolyacrylamide gel electrophoresis and Western blot analysis were carried out as described elsewhere [23]. The primary antibodies used were as follows: a rabbit polyclonal anti-p53 antibody (Cell Signaling Technology, Beverly, MA, USA); a mouse monoclonal anti-p21WAF1/ CIP1 antibody (MBL, Nagoya, Japan); and a mouse monoclonal antiglyceraldehyde 3-phosphate dehydrogenase (GAPDH) antibody (Organon Teknika, Durham, NC, USA). Immunoreactive proteins were visualized using enhanced chemiluminescence (ECL) detection system on a luminescent image analyser (LAS-4000, Fujifilm, Tokyo, Japan).

\section{Statistical analysis}

Experiments were performed in independent triplicates. All results are displayed as mean \pm standard error of the mean (SEM). Tests of significance were performed using unpaired t-student test (twotailed) with $\mathrm{p}<0.05$ considered to be statistically significant. Correlation coefficients $\left(\mathrm{r}^{2}\right)$ and their p-values (cut off $\left.\%=0.05\right)$ among data sets were calculated using GraphPad Prism 5 (GraphPad Software; San Diego, CA). 
Citation: Hassan MA, Furusawa Y, Okazawa S, Tobe K, Kondo T (2013) Evaluation of Sanazole Cytotoxicity in Human Drug-Sensitive and MDR Uterine Sarcoma Cells. Pharmaceut Anal Acta 4: 275. doi: 10.4172/2153-2435.1000275

Page 3 of 6

\section{Results and Discussion}

MES-SA/DX5 cells are the resistant counterpart of the human uterine sarcoma cell line MES-SA selected by continuous exposure to escalating doses of Dox [20]. The resistance in these cells has been mainly correlated to the overexpression of P-gp [25-28]. However, our previous work revealed that this cell line displays a weak phenotype of resistance with only one-third of the cells expressing P-gp, the thing that requires a booster Dox treatment of $500 \mathrm{nM}$ for $1 \mathrm{~h}$ every 8 splits [24]. For this study, MES-SA/DX5 cells were further selected and continuously maintained under nanomolar concentrations of Dox to maximize and maintain resistance. To confirm the efficiency of this procedure, one of the selected clones (clone V; hence MESSA/DX5v), MES-SA/DX5, and MES-SA cells were treated with serial concentrations of Dox for $24 \mathrm{~h}$ and their survival was assessed. As shown in Figure 2A, MES-SA/DX5v showed higher resistance to Dox compared to the original MES-SA/DX5 cells. The higher resistance encountered was associated with almost complete expression of P-gp

(A)

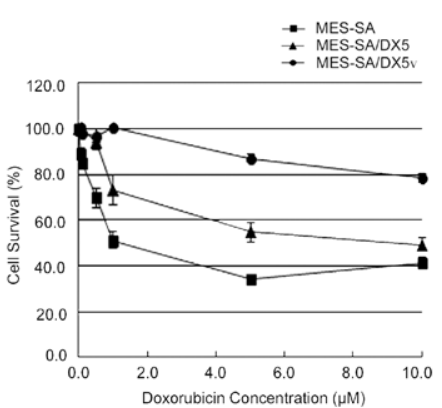

(B)

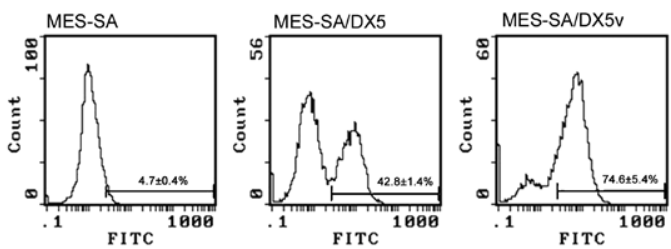

(C)

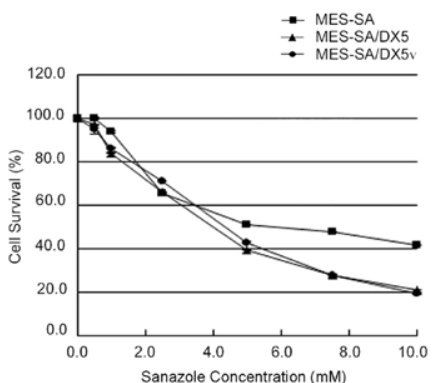

Figure 2: Differential responses of uterine sarcoma cell variants MES-SA MES-SA/DX5, and MES-SA/DX5v. Cell survival following $24 \mathrm{~h}$ incubation with a serial of Dox concentrations (A). Expression of P-gp under culture conditions (B). Cell survival following $24 \mathrm{~h}$ incubation with a serial of sanazole concentrations (C). Sanazole cytotoxicity is independent from P-gp expression in MES-SA/DX 5 and MES-SA/X5v cells. Data presented is the average \pm SEM of at least 3 independent replicates.
(Figure 2B). A similar assessment to sanazole cytotoxicity was carried out by exposing the three phenotypes to sanazole for $24 \mathrm{~h}$. The range of sanazole concentrations used has its median concentration $(5 \mathrm{mM})$ relevant to the dose administered intravenously to human subjects in clinical studies $[12,29]$. We noticed that both MES-SA/DX5 and MES$\mathrm{SA} / \mathrm{DX} 5 \mathrm{v}$ responded similarly indicating that sanazole effect might not rely on the extent of P-gp expression (Figure 2C). However, since MESSA/DX5v was continuously maintained in subcultures under $250 \mathrm{nM}$ Dox where Dox was only withdrawn before drug addition, MES-SA/ DX5v cells were used in subsequent experiments to ensure constant level of resistance through the study and to help evaluate the efficacy of sanazole treatment under Dox, a condition closer to in vivo.

The inspection of the survival data at $24 \mathrm{~h}$ shows clearly that at higher doses above $5 \mathrm{mM}$, the survival of the resistant cells was significantly lower than the parental cells. Taking into consideration a) The difference in doubling time of both cell variants (22-24 h for MES$\mathrm{SA}$ and $30 \mathrm{~h}$ for MES-SA/DX5), and $\mathrm{b}$ ) The relatively long elimination half-life of sanazole $\left(\mathrm{T}^{1} / 2 \beta \approx 35 \mathrm{~h}\right.$ [29]), cell survival was also evaluated after $48 \mathrm{~h}$ treatment. Interestingly, both cell variants displayed similar survival percentages at all sanazole doses after $48 \mathrm{~h}$ exposure (Figure 3 ). Sanazole concentrations required to kill $50 \%$ of cell population (EC50) based on 24 and $48 \mathrm{~h}$ survival data were 6.5 and $1.9 \mathrm{mM}$ for MES-SA cells, and 3.3 and $1.8 \mathrm{mM}$ for MES-SA/DX5 cells, respectively. These results collectively reflect the efficiency of the drug as an anticancer agent regardless of drug resistance under our study conditions.

Despite the similar survival patterns, the underlying events showed significant differences between both cell phenotypes. For instance, in cell cycle analyses of treated cells, MES-SA and MES-SA/DX5v showed significant arrest in different cell cycle phases, namely, G1- and S-phases, respectively (Figures $4 \mathrm{~A}-\mathrm{D}$ ). Following a $48 \mathrm{~h}$ - incubation period with the drug, the cell cycle retained the respective arrest pattern even at lower doses of the drug (Figures 4B and 4D). Mitsuhashi et al. [30] has previously reported a similar G1 arrest in rodent cells after exposure

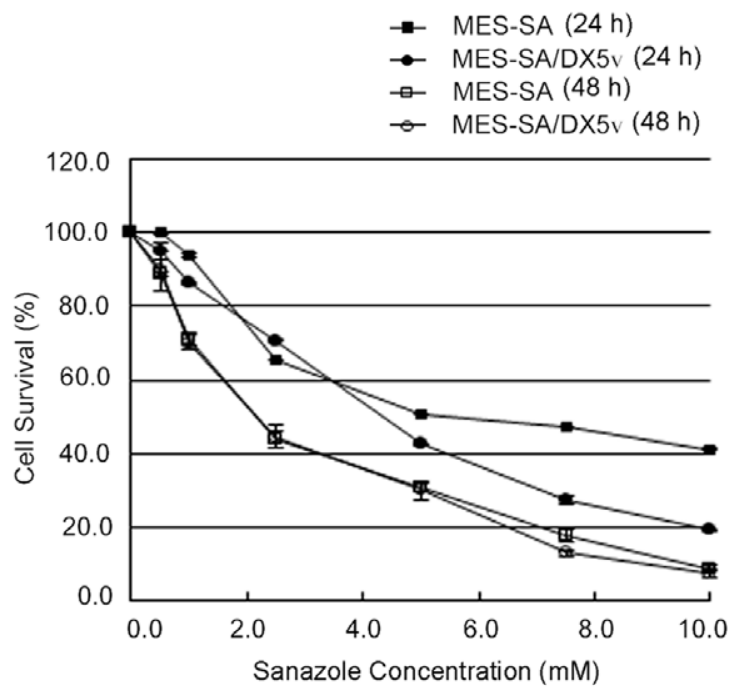

Figure 3: Dose response curves of sanazole cytotoxicity. Cell survival was assessed after 24 or $48 \mathrm{~h}$ treatment with a serial concentrations of sanazole in MES-SA and MES-SA/DX5v cells. Data presented is the average \pm SEM of at least 3 independent replicates. 
Citation: Hassan MA, Furusawa Y, Okazawa S, Tobe K, Kondo T (2013) Evaluation of Sanazole Cytotoxicity in Human Drug-Sensitive and MDR Uterine Sarcoma Cells. Pharmaceut Anal Acta 4: 275. doi: 10.4172/2153-2435.1000275

Page 4 of 6

to sanazole for $24 \mathrm{~h}$ [30]. The similar results obtained in our study suggest that the underlying mechanism might be conserved among vertebrates. MES-SA cells are reported to possess a wild type p53 [31] which is activated upon sensing DNA damage and consequently upregulates the cyclin dependent kinase inhibitor (CKI) p21 inducing a G1 arrest [32]. This scenario was confirmed in western blot results shown in Figure 4E. MES-SA/DX5v cells seemed to have an impaired p53 - functionality and thus p21, a typical downstream target of p53, could not be activated resulting in an initial escape from a similar G1 arrest. This could be in addition to the reported invariability in Annexin A7 expression in response to Dox treatment which allows MES-SA/ DX5 cells to escape G1 arrest [28]. However, the cells were instead trapped in the S-phase possibly upon the activation of the intra-S-phase checkpoint which is beyond the control of p53 and p21 [32-34]. On the other hand, the inspection of the subG1 fraction (supposedly apoptotic cells with fragmented DNA) showed that it increased proportionally in both cell lines. The maximum subG1 fraction observed was $>2.5$-fold higher in MES-SA/DX5v cells compared to MES-SA cells. This ratio was conserved after $48 \mathrm{~h}$ - incubation period with half of the sanazole dose. Further statistical analysis of the cell cycle data revealed a sort of negative linear correlation between cell polyploidy and apoptosis induction. The correlation was also stronger in MES-SA/DX5v cells as compared to MES-SA cells (correlation coefficients $\left(\mathrm{r}^{2}\right)$ were -0.46 $(\mathrm{p}=0.54)$ and $-0.94(\mathrm{p}=0.06)$ at $24 \mathrm{~h}$ and $-0.14 \quad(\mathrm{p}=0.83)$ and -0.85 $(\mathrm{p}=0.07)$ at $48 \mathrm{~h}$ for MES-SA and MES-SA/DX5v, respectively). This decrease may indicate that the resistant cells were encountering massive DNA damage that could not be repaired or overcome, the thing that culminated in possibly cell death as manifested by the higher percentage of cells in SubG1 fraction. To test this hypothesis, we analysed the presence and the extent of phosphorylated H2AX foci $(\gamma \mathrm{H} 2 \mathrm{AX})$ flow cytometrically in comparison to Dox $(1 \mu \mathrm{M})$. Figure 5 shows that MES-SA/DX5v cells had higher mean fluorescence intensities at all sanazole doses in contrast to Dox treatment which exerts its maximum cell killing effect preferentially in MES-SA cells at $1 \mu \mathrm{M}$ dose [24]. It is worth mentioning that the evaluation of $\gamma \mathrm{H} 2 \mathrm{AX}$ after $24 \mathrm{~h}$ of treatment might be interpreted as being partially a consequence of apoptosis as well as a consequence of DNA damage induced by sanazole [35]. The correlation between subG1 fraction and the extent of $\gamma \mathrm{H} 2 \mathrm{Ax}$ yielded
(A)

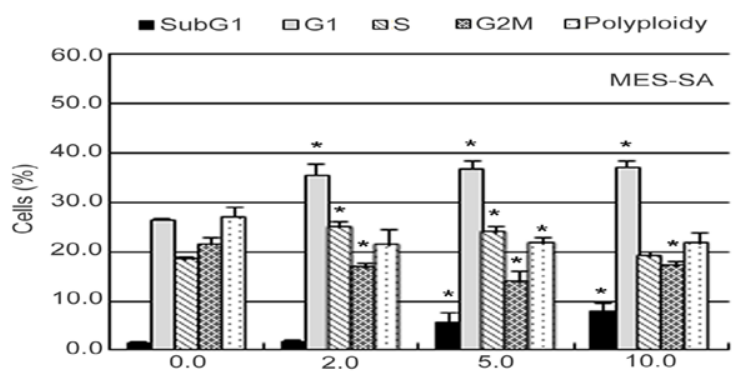

(C)

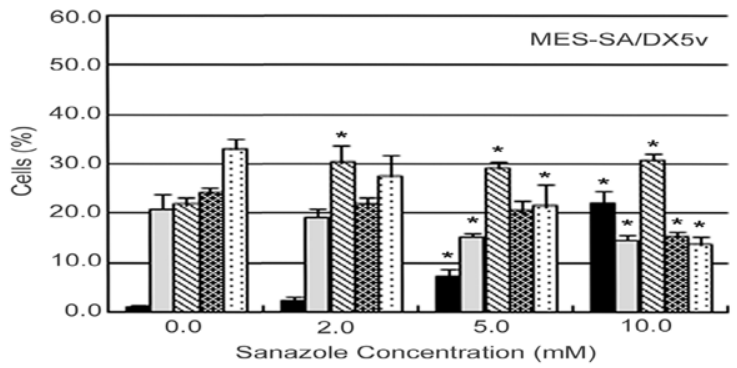

(B)

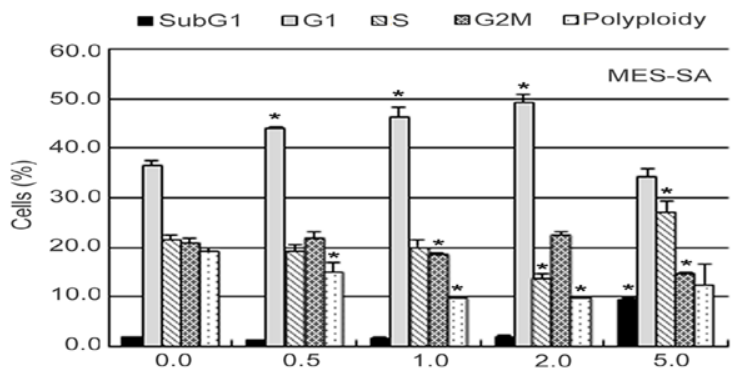

(D)

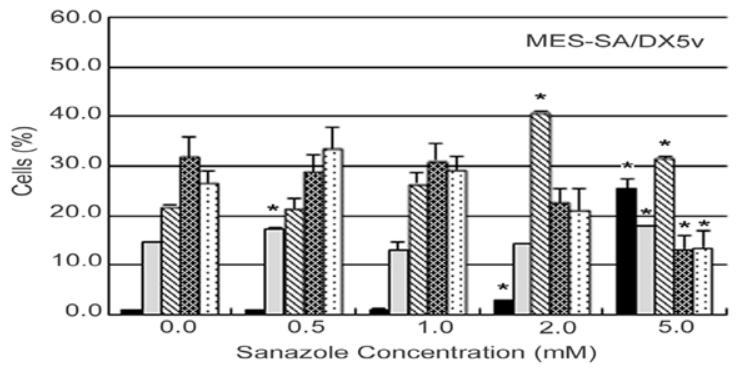

(E)

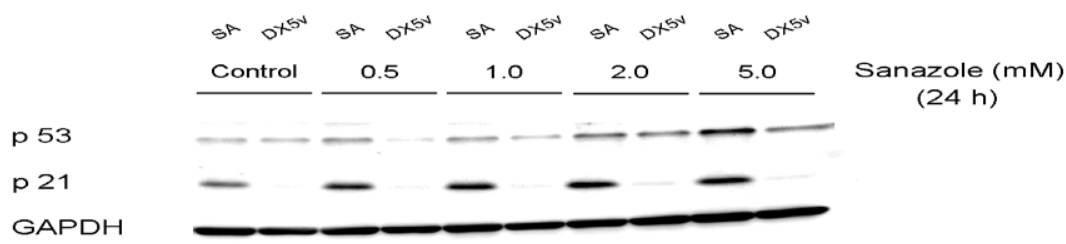

Figure 4: Changes in cell cycle and the expression of some relevant proteins by sanazole treatment. Cell cycle analyses in treated MES-SA cells showing $\mathrm{G}$ arrest after $24 \mathrm{~h}$ treatment with sanazole at 2,5 and $10 \mathrm{mM}(\mathrm{A})$, and after $48 \mathrm{~h}$ treatment with sanazole at $0.5,1,2$ and $5 \mathrm{mM}(\mathrm{B})$. In treated MES-SA/DX5v cells, S-phase arrest was observed after $24 \mathrm{~h}$ treatment with sanazole at 2,5 and $10 \mathrm{mM}(\mathrm{C})$, and after $48 \mathrm{~h}$ treatment with sanazole at $0.5,1,2$ and $5 \mathrm{mM}(\mathrm{D})$. Asterisks $\left({ }^{*}\right)$ indicate statistical significance $(\mathrm{p}<0.05)$. Western blot analysis shows the expression of p53 and p21 proteins following a $24 \mathrm{~h}$-incubation period with different doses of sanazole $(\mathrm{E})$ 


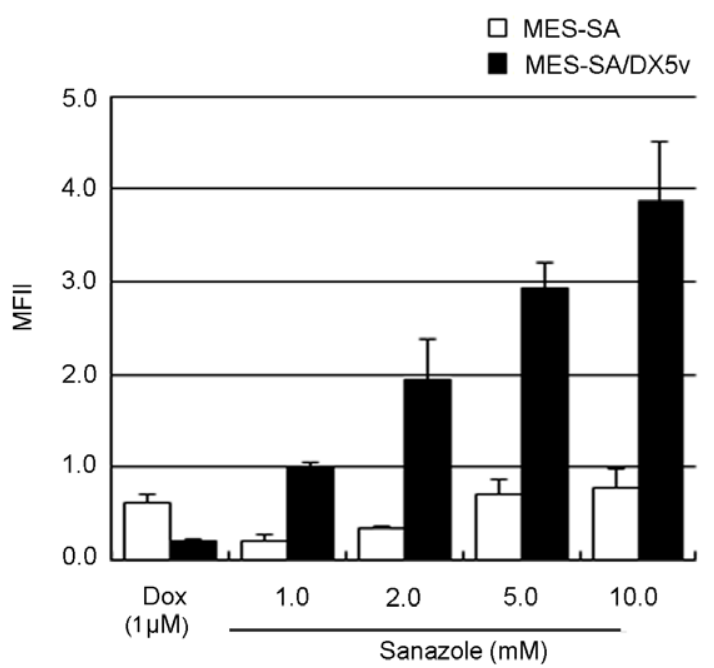

Figure 5: H2AX phosphorylation. The mean fluorescence intensity (MFI) of labeled $\mathrm{YH} 2 \mathrm{AX}$ in control and treated MES-SA and MES=SA/DX5v cells was detected flow cytometrically $24 \mathrm{~h}$ after treatment. Dox $(1 \mu \mathrm{M})$ was used as a positive control. For quantification of data, the mean fluorescence intensity index (MFII) was calculated as follows: (MFI of treated cells - MFI of control cells) / MFI of control.

higher coefficient with MES-SA cells $(0.951, \mathrm{p}=0.05)$ compared to MES-SA/DX5v cells $(0.83, \mathrm{p}=0.174)$. Thus, the data as such supports that the DNA damage observed in MES-SA/DX5v cells might be a causative rather than a consequence.

The assessment of intracellular ROS elevation showed that ROS were involved early in the cellular response to sanazole. Figure 6 shows that sanazole treatment primarily induced superoxide anion $\left(\mathrm{O}_{2}^{-}\right.$-.) elevation whereas the peroxides production was generally lower in comparison in both cell variants. This differential elevation in intracellular ROS might be dependent on cell type as shown in previous studies $[17,18]$. Also, the data shows that the resistant cells always possessed lower intracellular ROS levels, especially at higher doses, which might be due to the so-called adaptive antioxidant response [22].

The compilation of the results presented here suggests that sanazole is a potent cytostatic agent that is not a substrate to P-pg and its mechanism of action is apparently independent from multidrug resistance displayed by the cells under study. Sanazole also may possibly have a different target site(s) compared to Dox. If this holds true, we would expect an additive effect if sanazole is given in combination with Dox. To prove this assumption, we assessed cell survival after adding Dox and sanazole simultaneously to MES-SA or MES-SA/DX5v cells. Different doses of Dox were selected to represent the reported three cell death modes induced by Dox [24,36], namely $0.1,1$ and $10 \mu \mathrm{M}$, whereas sanazole was added at a concentration of $2 \mathrm{mM}$ as an intermediate dose in the range employed in this study and a dose that corresponds to clinical concentrations. A $24 \mathrm{~h}$-incubation period with both drugs showed an additive decrease in cell survival under all treatment conditions (Figure 7). Interestingly, this additive response was observed in both cell variants confirming that the cytotoxicity of sanazole is mediated through different pathways than those underlying the cytotoxicity of Dox and thus independently from resistance.

In conclusion, this study confirms the antitumor and the cytostatic activity of sanazole under aerobic conditions in human cells. It also
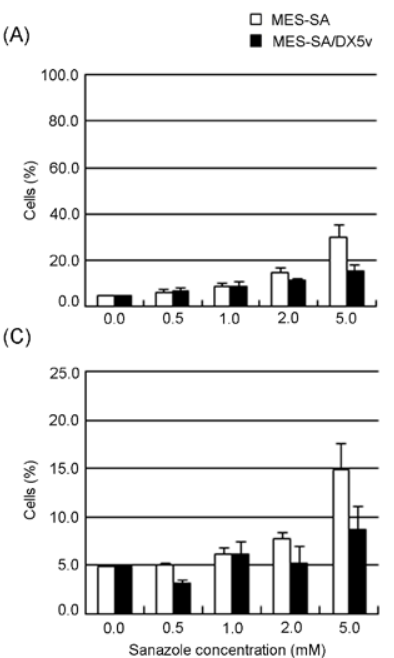

(D)
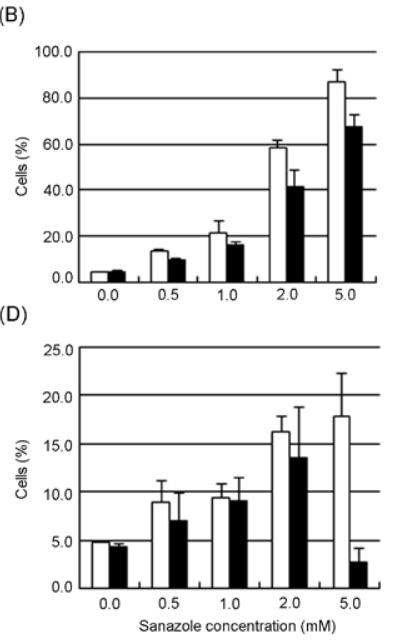

Figure 6: Intracellular ROS elevation by sanazole treatment. Sanazole was added at different concentrations to cultured MES-SA and MES-SA/DX5V. Samples were collected at $6 \mathrm{~h}(\mathrm{~A} \& \mathrm{C})$ and $24 \mathrm{~h}(\mathrm{~B} \& D)$. Control and treated samples were analysed flow cytometrically for superoxide anion $\left(\mathrm{O}_{2}-\right.$.) elevation using hydroethidine (HE) (A\&B), and for peroxides elevation using dichlorofluorescein acetate (DCFH-DA) (C\&D).

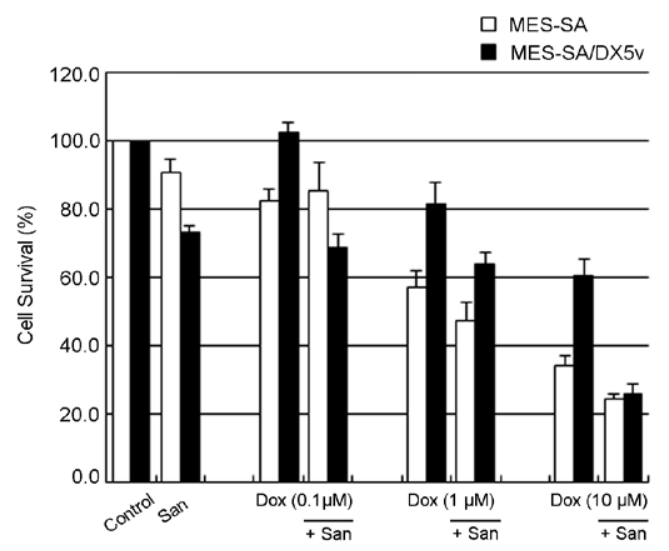

Figure 7: Simultaneous combination of sanazole and doxorubicin. Cell survival of MES-SA and MES-SA/DX5v cells treated with $2 \mathrm{mM}$ of sanazole and $0.1,1$ or $10 \mu \mathrm{M}$ of doxorubicin simultaneously for $24 \mathrm{~h}$.

highlights its efficiency against MDR cells where it could exert its action independently from P-gp overexpression and probably from other mechanisms for resistance. Although the initial sensitivity of MES-SA/DX5v cells compared to its parental counterpart after $24 \mathrm{~h}$ treatment can be justified by the doubling time differences, it might be possible that the altered proteomics of the resistant cells facilitate a prompt bioactivation of the drug. Resistant cells have been reported to undergo an adaptive antioxidant mechanism through the modulation of the expression of certain enzymes so that they can acquire protection against oxidative stress induced by pro-oxidant chemotherapeutics such as Dox [22]. Available data shows that this scenario occurs in MESSA/DX5 cells ([28], unpublished data) during acquiring resistance. An enzyme of interest is the xanthine oxidoreductase enzyme encoded in human by the gene HDX. This particular enzyme has been reported to be involved in the bioactivation of sanazole to exert its antitumor and radiosensitizing effects [15]. 
Although the role of sanazole in reversing MDR has been previously reported, this study aspires its novelty in the utilization of human cells, in contrast to the previous studies which withdrew their conclusions from rodent cells $[37,38]$. Also, this study provides an insight of some of the molecular events involved and opens the way for considering other bioreductive drugs that are refractory to P-gp efflux as possible chemotherapeutics against multidrug resistant cancer cells.

\section{Acknowledgment}

Financial support for this study was provided by a Grant-in-Aid for Scientific Research (B) (22390229), Japan Society for the Promotion of Science (to TK), and by research grant from International Association of Sensitization for Cancer Treatment (IASCT) (to MA). The funders had no role in study design, data collection and analysis, decision to publish, or preparation of the manuscript.

\section{References}

1. Hall MD, Handley MD, Gottesman MM (2009) Is resistance useless? Multidrug resistance and collateral sensitivity. Trends Pharmacol Sci 30: 546-556.

2. Darby RA, Callaghan R, McMahon RM (2011) P-glycoprotein inhibition: the past, the present and the future. Curr Drug Metab 12: 722-731.

3. Regev R, Assaraf YG, Eytan GD (1999) Membrane fluidization by ether, other anesthetics, and certain agents abolishes P-glycoprotein ATPase activity and modulates efflux from multidrug-resistant cells. Eur J Biochem 259: 18-24.

4. Liu Y, Cho CW, Yan X, Henthorn TK, Lillehei KO, et al. (2001) Ultrasound-Induced hyperthermia increases cellular uptake and cytotoxicity of P-glycoprotein substrates in multi-drug resistant cells. Pharm Res 18: 1255-1261.

5. Shao ZY, Zhai BJ, Zhao CL, Hu K, Shen DM, et al. (2008) Cytotoxic effects and in vitro reversal of multidrug resistance by therapeutic ultrasound in human hepatocarcinoma cell line (HepG2). Ultrasonics 48: 297-302.

6. Alakhova DY, Rapoport NY, Batrakova EV, Timoshin AA, Li S, et al. (2010) Differential metabolic responses to pluronic in MDR and non-MDR cells: a novel pathway for chemosensitization of drug resistant cancers. J Control Release 142: 89-100.

7. Hu CM, Zhang L (2012) Nanoparticle-based combination therapy toward overcoming drug resistance in cancer. Biochem Pharmacol 83: 1104-1111.

8. Lage H (2006) MDR1/P-glycoprotein (ABCB1) as target for RNA interferencemediated reversal of multidrug resistance. Curr Drug Targets 7: 813-821.

9. Shibamoto Y, Sakano K, Kimura R, Nishidai T, Nishimoto S, et al. (1986) Radiosensitization in vitro and in vivo by 3-nitrotriazoles. Int J Radiat Oncol Bio Phys 12: 1063-1066.

10. Dobrowsky W, Huigol NG, Jayatilake RS, Kizilbash NI, Okkan S, et al. (2005) AK-2123 (Sanazol) as a radiation sensitizer in the treatment of stage III cancer cervix: initial results of an IAEA multicentre randomized trial. J Cancer Res Ther 1: 75-78.

11. Dobrowsky W, Huigol NG, Jayatilake RS, Kizilbash NI, Okkan S, et al. (2007) AK-2123 (Sanazol) as a radiation sensitizer in the treatment of stage III cervical cancer: results of an IAEA multicentre randomised trial. Radiother Oncol 82 24-29.

12. Ullal SD, Shenoy KK, Pai MR, Chowta MN, Adiga SM, et al. (2006) Safety and radiosensitizing efficacy of sanazole (AK 2123) in oropharyngeal cancers: randomized controlled double blind clinical trial. Indian J Cancer 43: 151-155.

13. Konovalova NP, Volkova LM, Tatyanenko LV, Kotelnikova RA, Yakushchenko TN, et al. (1997) Inhibitory effect of radiosensitizer AK-2123 on experimental hepatic metastases and Ca2+ active transport. Neoplasma 44: 361-365.

14. Konovalova NP, Diatchkovskaya RF, Volkova LM, Kagiya TV (1995) Radiosensitizer AK-2123 as modulating agent in the chemotherapy of experimental metastases. Neoplasma 42: 119-122.

15. Schepetkin IA, Cherdyntseva NV, Kagiya VT (2001) Sanazole as substrate of xanthine oxidase and microsomal NADPH/cytochrome P450 reductase. Pathophysiology 8: 119-127.

16. Yu DY, Zhao QL, Wei ZL, Nomura T, Kashiwakura I, et al. (2009) Enhancement of radiation-induced apoptosis of human lymphoma U937 cells by sanazole. Apoptosis 14: 655-664

17. Yu DY, Zhao QL, Wei ZL, Shehata M, Kondo T (2009) Enhancement of hyperthermia-induced apoptosis by sanazole in human lymphoma U937 cells Int J Hyperthermia 25: 364-373.

18. Hassan MA, Furusawa Y, Zhao QL, Takasaki I, Feril Jr. LB, et al. (2011) Differential cytotoxicity and sonosensitization by sanazole: effect of cell type and acoustic parameters. J Med Ultrason 38: 65-72.

19. Harker WG, MacKintosh FR, Sikic BI (1983) Development and characterization of a human sarcoma cell line, MES-SA, sensitive to multiple drugs. Cancer Res 43: $4943-4950$.

20. Harker WG, Sikic BI (1985) Multidrug (pleiotropic) resistance in doxorubicinselected variants of the human sarcoma cell line MES-SA. Cancer Res 45 4091-4096.

21. Wang Y, Arriaga EA (2008) Monitoring incorporation, transformation and subcellular distribution of N-I-leucyl-doxorubicin in uterine sarcoma cells using capillary electrophoretic techniques. Cancer Lett 262: 123-132.

22. Kalinina EV, Chernov NN, Saprin AN, Kotova YN, Andreev YA, et al. (2006) Changes in expression of genes encoding antioxidant enzymes, heme oxygenase-1, Bcl-2, and $\mathrm{Bcl}-\mathrm{xl}$ and in level of reactive oxygen species in tumo cells resistant to doxorubicin. Biochemistry (Mosc) 71: 1200-1206.

23. Furusawa Y, Fujiwara Y, Campbell P, Zhao QL, Ogawa R, et al. (2012) DNA double-strand breaks induced by cavitational mechanical effects of ultrasound in cancer cell lines. PLoS One 7: e29012.

24. Hassan MA, Furusawa Y, Minemura M, Rapoport N, Sugiyama T, et al. (2012) Ultrasound-induced new cellular mechanism involved in drug resistance. PLoS One 7: e48291.

25. Chen G, Durán GE, Steger KA, Lacayo NJ, Jaffrézou JP, et al. (1997) Multidrug-resistant human sarcoma cells with a mutant P-glycoprotein, altered phenotype, and resistance to cyclosporins. J Biol Chem 272: 5974-5982.

26. Liu FS (2009) Mechanisms of chemotherapeutic drug resistance in cancer therapy--a quick review. Taiwan J Obstet Gynecol 48: 239-244.

27. Chen KG, Wang YC, Schaner ME, Francisco B, Durán GE, et al. (2005) Genetic and epigenetic modeling of the origins of multidrug-resistant cells in a human sarcoma cell line. Cancer Res 65: 9388-9397.

28. Lin ST, Chou HC, Chang SJ, Chen YW, Lyu PC, et al. (2012) Proteomic analysis of proteins responsible for the development of doxorubicin resistance in human uterine cancer cells. J Proteomics 75: 5822-5847.

29. Huan LC, Hua BY (1994) Clinical pharmacokinetic study and sensitive effect of AK-2123. Int J Radiat Oncol Biol Phys 29: 607-610.

30. Mitsuhashi N, Sakurai H, Takahashi T, Akimoto T, Higuchi K, et al. (1998) Does AK-2123 (Senazole) have sensitizing effects on radiation, cisplatin and hyperthermia under aerobic conditions in vitro? Anticancer Res 18: 3463-3467.

31. Tian K, Wang $\mathrm{Y}, \mathrm{Xu} \mathrm{H}$ (2007) WTH3 is a direct target of the p53 protein. $\mathrm{Br} J$ Cancer 96: 1579-1586

32. Davoli T, de Lange T (2011) The causes and consequences of polyploidy in normal development and cancer. Annu Rev Cell Dev Biol 27: 585-610.

33. Bartek J, Lukas J (2001) Mammalian G1- and S-phase checkpoints in response to DNA damage. Curr Opin Cell Biol 13: 738-747.

34. Gottifredi V, Shieh S, Taya Y, Prives C (2001) p53 accumulates but is functionally impaired when DNA synthesis is blocked. Proc Natl Acad Sci U S A 98: 1036-1041.

35. Furusawa Y, Zhao QL, Hassan MA, Tabuchi Y, Takasaki I, et al. (2010) Ultrasound-induced apoptosis in the presence of Sonazoid and associated alterations in gene expression levels: a possible therapeutic application. Cancer Lett 288: 107-115.

36. Rebbaa A, Zheng X, Chou PM, Mirkin BL (2003) Caspase inhibition switches doxorubicin-induced apoptosis to senescence. Oncogene 22: 2805-2811.

37. Goncharova SA, Rajewskaya TA, Konovalova NP, Kagiya TV (2001) Nitrotriazole AK-2123 enhances mitomycin C activity in mice bearing multidrugresistant tumors. J Chemother 13: 635-640.

38. Konovalova NtP (2003) Ultralow doses of various drugs in chemotherapy of experimental tumors. Bull Exp Biol Med 135 Suppl 7: 45-47. 